\title{
Ground-State Diffuse Reflectance and Laser-Induced Luminescence on the Evaluation of Total PAHs in Urban Air Particulate Matter from Rio de Janeiro City in Brazil
}

\author{
Anabela S. Oliveira ${ }^{* a}$, Milena B. Fernandes ${ }^{b}$, Josino C. Moreira ${ }^{b}$ and Luis F. Vieira Ferreira ${ }^{a}$ \\ ${ }^{a}$ Centro de Química - Física Molecular, Complexo I, Instituto Superior Técnico, Av. Rovisco Pais 1096 \\ Lisboa Codex, Portugal \\ ${ }^{b}$ Centro de Estudos da Saúde do Trabalhador e Ecologia Humana, Escola Nacional de Saúde Pública, Fundação \\ Oswaldo Cruz, Rua Leopoldo Bulhões 1480, 21041-210, Rio de Janeiro - RJ, Brazil
}

\begin{abstract}
As técnicas de reflectância difusa no estado fundamental e de fluorescência induzida por laser foram testadas na avaliação do teor total de hidrocarbonetos policíclicos aromáticos (PAHs) em particulado atmosférico não extraído e não fraccionado. Foi comparado o teor total de PAHs no particulado estimado por estes métodos e por cromatografia gasosa em amostras de particulado atmosférico coletado na cidade do Rio de Janeiro e ainda para o material padrão de referência (SRM) 1648. A reflectância difusa no estado fundamental provou ser uma boa técnica para estimar o teor total de PAHs em material urbano particulado, uma vez que os resultados se correlacionam diretamente com os dados obtidos pela técnica de cromatografia gasosa convencional. A fluorescência induzida por laser é também um método eficiente para estimar baixas concentrações. Ocorrem desvios aparentes na resposta da fluorescência devido à interferência do "black carbon" que têm de ser contabilizados. Estes métodos ópticos mostraram ser rápidos, de baixo custo, sensíveis e úteis como técnicas de monitoramento, permitindo medidas de campo.
\end{abstract}

Ground-state diffuse reflectance and laser-induced fluorescence techniques were tested on the evaluation of total polycyclic aromatic hydrocarbons (PAHs) in unextracted and unfractionated airborne particulate matter. The total particulate PAH content estimated from these methods and from gas-chromatography in air particulate samples collected in the Rio de Janeiro city and for standard reference material (SRM) 1648, were compared. Ground-state diffuse reflectance proved to be by itself a good technique for estimating total PAH content in urban particulate matter, since results directly correlate with data obtained by conventional gas-chromatographic techniques. Laser-induced fluorescence is also an efficient method for low concentration estimates. Apparent deviations of the fluorescence response do occur due to black carbon interference and have to be taken into account. These surface optical methods showed to be fast, low cost, sensitive and useful as screening techniques, allowing field measurements.

Keywords: air quality monitoring techniques, air particulate matter, polycyclic aromatic hydrocarbons, ground-state diffuse reflectance, laser-induced fluorescence

\section{Introduction}

The development of diffuse reflectance and laserinduced luminescence (both fluorescence and phosphorescence) techniques made possible the study of photophysical and photochemical processes of probes adsorbed on opaque heterogeneous supports. ${ }^{1-6}$ These processes are strongly dependent on the probes-matrix interactions. ${ }^{7}$ Room-temperature luminescence may be

\footnotetext{
* e-mail: asoliveira@ ist.utl.pt
}

effectively enhanced by the rigid environment frequently provided by the solid support. ${ }^{8-11}$ This fact can be successfully used on the determination of trace levels of luminescent probes adsorbed on surfaces. ${ }^{11-13}$

In urban areas, outdoor air pollution is chiefly associated with the incomplete combustion of organic fuels in automobile engines and industrial plants and the consequent emission of soot particles mostly in the breathable size range. Black carbon is the most refractory fraction of soot particles and is formed of a graphitic polymerised backbone with organic functionalities. ${ }^{14}$ It contains a complex mixture of organic compounds, several 
of whom have toxic effects on human health, such as the polycyclic aromatic hydrocarbons (PAHs). The latter comprehend a group of chemical substances some of them possessing mutagenic/carcinogenic activities and therefore considered as target pollutants for environmental monitoring. ${ }^{15}$

Since PAHs are spread in the environment adsorbed or included in complex matrices, laboratory procedures used in their determination are, in general, expensive and timeconsuming. The most common methods for individual determinations involve extraction of particulate matter with organic solvents, column or thin layer chromatography to eliminate interfering substances, followed by detection with gas chromatography/mass spectrometry (GC/MS) or high performance liquid chromatography (HPLC). ${ }^{16}$

The aim of this work was to test the use of ground-state diffuse reflectance (GSDR) and laser-induced fluorescence (LIF) as screening methods for monitoring total PAHs in air particulate matter. For this purpose, 12 filters containing particulate matter collected in the city of Rio de Janeiro (Brazil) and a sample of an urban particulate standard reference material (SRM 1648) were analysed. The obtained results were compared with those obtained by chromatographic techniques. ${ }^{17,18}$ To the best of our knowledge, this is the first attempt to combine these two surface photochemical techniques for the analysis of total PAHs in actual atmospheric samples.

\section{Experimental}

\section{Materials and methods}

Urban particulate matter was collected by filtration of approx. $600 \mathrm{~m}^{3}$ of ambient air on quartz membrane filters using a high volume air sampler, in December 1998, January and March 1999 (the summer months in Southern Hemisphere). Samples were collected at four air monitoring stations with different traffic influences: Alto da Boa Vista (Alto), Ilha do Governador (Ilha), City Center (Center) and Brasil Avenue (Brasil). ${ }^{18}$ The first two sites are located in residential areas, while sampling stations at the City Center and Brasil Avenue are located in business districts within $50 \mathrm{~m}$ from main traffic corridors. Filters were analysed for PAHs as described by Fernandes et al. ${ }^{18}$ using conventional techniques of organic solvent extraction, silica gel column chromatography and GC/MS in the selected ion monitoring (SIM) mode. Approximately $1 / 8$ of each filter was kept for latter testing by new complementary techniques.

The urban air particulate standard reference material (SRM 1648) was obtained from the Office of Standard
Reference Materials, National Institute of Standards and Technology, Gaithersburg, USA. This SRM was collected in St. Louis (MO), USA, over a period in excess of 12 months and is intended for use as a control material in the evaluation of methods to analyse urban particulate matter. Wise et $a l .{ }^{17}$ calculated PAH levels in SRM 1648 from both GC/MS and HPLC responses.

Powdered model samples were prepared by deposition of pyrene (Aldrich, 99\%, optical grade) on silica (60A, 70230 mesh, Merck) and activated charcoal (GR for analysis, Merck) by slow ethanol (Uvasol grade, Merck) evaporation as described in detail by Vieira Ferreira et al. ${ }^{8,9}$

Ground-state absorption spectra of all samples in the UV-vis regions were registered from 220 to $900 \mathrm{~nm}$ using an OLIS 14 UV/VIS/NIR spectrophotometer with a diffuse reflectance attachment. The integrating sphere is $90 \mathrm{~mm}$ in diameter and is internally coated with a standard white coating. The standard apparatus was modified to include the possibility of using short-wave pass filters (UG5), which prevent sample fluorescence from reaching the detector. Reflectance from filter samples was measured from $\sim 2 \mathrm{~cm}^{2}$ of their surface placed against a quartz cell wall. All filters are optically thick.

The reflectance, $\mathrm{R}$, from each sample was obtained by scanning the excitation monochromator in the adequate wavelength region; the remission function, $F(R)$, was calculated using the Kubelka-Munk equation, defined by Eq. (1):

$\mathrm{F}(\mathrm{R})=(1-\mathrm{R})^{2} /(2 \mathrm{R})=\mathrm{K} / \mathrm{S}$

The Kubelka-Munk equation applies to optically thick samples, i.e., those where any further increase in thickness does not affect the experimentally determined reflectance R. K and S are the absorption and scattering coefficients with dimensions (distance) $)^{-1}$. For an ideal diffuser, where the radiation has the same intensity in all directions, $\mathrm{K}=$ ${ }_{2 \varepsilon} \mathrm{C}$ ( $\varepsilon$ is the Naperian absorption coefficient, $\mathrm{C}$ is the concentration). Since the substrate usually absorbs at the excitation wavelength, $\lambda_{\mathrm{e}}$,

$\mathrm{F}(\mathrm{R})_{\text {sample }}=\mathrm{F}(\mathrm{R})_{\text {total }}-\mathrm{F}(\mathrm{R})_{\text {blank }}=\sum_{\mathrm{i}} 2 \varepsilon_{\mathrm{i}} \mathrm{C}_{\mathrm{i}} / \mathrm{S}$

where $F(R)_{\text {blank }}$ is obtained for the blank (filter). This equation predicts a simple linear relation for the remission function of the probe as a function of concentration (for a constant scattering coefficient) whenever the probe is in the form of a monomer.

Further experimental details and description of system calibration used to obtain accurate reflectance (R) measurements are given by Vieira Ferreira et al..$^{8,9}$ 
Fluorescence emission measurements of the samples were performed in a front-surface arrangement, at room temperature $\left(20 \pm 1^{\circ} \mathrm{C}\right)$, in the laser-induced time-resolved luminescence system of Figure 1. The system uses the $337.1 \mathrm{~nm}$ pulse (suitable for PAH excitation) of a $\mathrm{N}_{2}$ laser $(1.3 \mathrm{~mJ} /$ pulse) as excitation source, coupled to a delay unit and a gated intensified charge-coupled device and enables luminescence measurements on the nanosecond to the milisecond time range. ${ }^{6,11,19}$ Results are presented as the average of at least three independent measurements taken from different zones of each filter, the excitation pulse irradiates about $0.5 \mathrm{~cm}^{2}$.

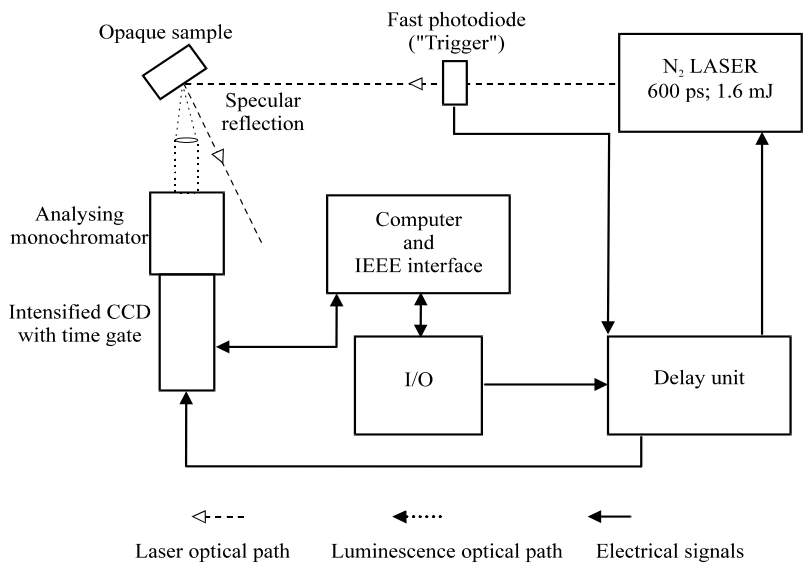

Figure 1. Schematic diagram of the laser-induced luminescence apparatus

It is important to notice that both reflectance and fluorescence measurements of the filters were made directly, without any treatment.

\section{Results and Discussion}

Figure 2 shows the ground-state diffuse reflectance spectra of the filters and SRM 1648 at the PAHs absorption wavelength zone. In all the spectral range, no individual bands could be identified. Sample spectra are characterised by an intense broad absorption that only slightly decreases with wavelength. The reflectance is characteristic of each collection station, decreasing progressively in the order Alto, Ilha, Center, Brasil. This order is that of increasing PAH content of the samples as determined elsewhere ${ }^{18}$ by GC/MS and shown in Figure $3 a$ and $3 b$. As can be seen in Figure $3 \mathrm{c}$, this tendency was fully confirmed by comparing the remission functions of each sample. We also analysed SRM 1648 and observed that its absorption spectra has the same typical shape of any other sample (Figure 2), being as intense as those from Brasil Avenue (Figure 3c).

The absence of distinguishable bands in Figure 2 suggests that the reflectance is not directly determined by

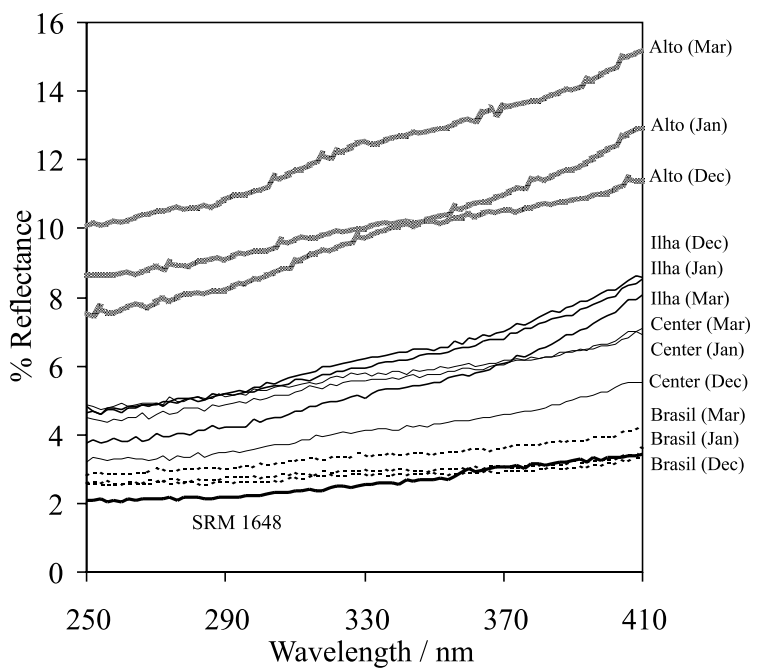

Figure 2. Reflectance spectra of SRM 1648 and of urban air particulate matter samples from four collecting points in Rio de Janeiro City in December, January and March and SRM 1648

individual PAHs. The fact that samples vary from light to dark grey indicates an increasing black carbon content with colour. However, Ilha samples are distinct and brownish in colour. This deviation might derive from a larger amount of yellowish plant organic carbon ${ }^{14}$, as also suggested by higher $n$-alkane carbon preference index (CPI) values. ${ }^{20}$

The samples were further analysed by laser-induced fluorescence. Figure 4 plots the fluorescence spectra for each collection point in December and for SRM 1648. Although all filters display approximately the same fluorescence band peaking at $430 \mathrm{~nm}$, their intensity clearly depends on the collection station, as shows Figure 3d. For SRM 1648, the fluorescence spectra have a similar shape to that of the filters and its intensity is close to that of the most contaminated samples. As a general rule the fluorescence intensity of the filters (on December and January) increase from Alto to Center as observed for total PAH content (Figure 3a and 3b). The fluorescence from Brasil samples and SRM 1648 is considerably lower than expected. In despite of that, fluorescence measurements appear to reproduce accurately the changes on PAH levels for the other three stations and also for each individual station.

As mentioned earlier, ${ }^{14,15}$ black carbon is a key-carrier phase for atmospheric PAHs. We postulate that its increasing content from Alto to Brasil could be responsible for a progressive fluorescence quenching effect, which maximises at the most concentrated samples (SRM 1648 and Brasil). Indeed, black carbon is a highly effective lightabsorber, being known as very close to true black $(\mathrm{R}=0)$.

In order to test the hypothesis above, we prepared samples with $10 \mathrm{ng} \mathrm{mg}^{-1}$ of pyrene deposited onto silica 

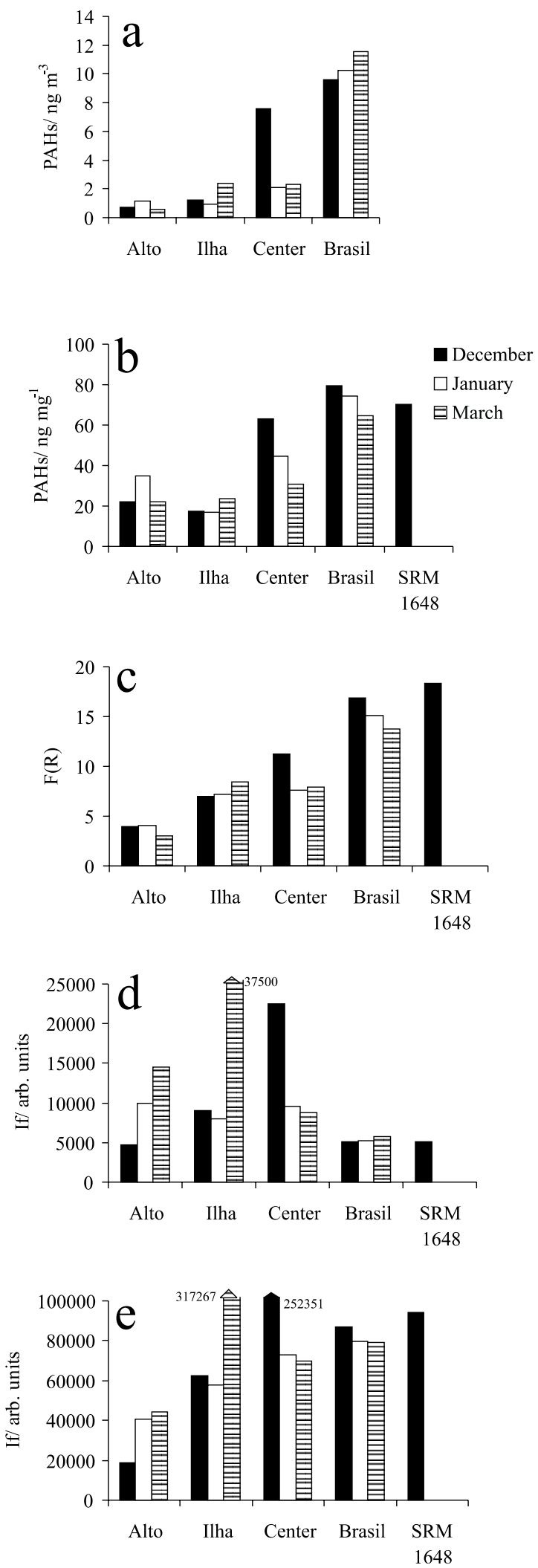

Figure 3. (a, b) Plot of total PAH content a) per volume, b) per mass measured using chromatographic techniques (references 17, 18 and 20), (c) Remission function, (d) Laser Induced fluorescence intensity, (e) Black Carbon corrected fluorescence intensity of urban air particulate matter samples from Rio de Janeiro city and SRM 1648

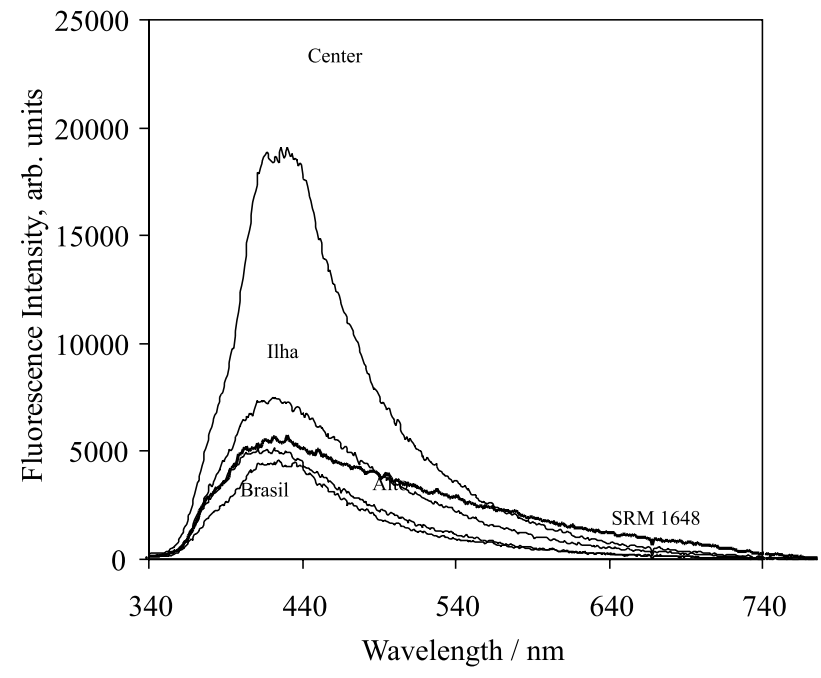

Figure 4. Laser-induced fluorescence spectra of urban air particulate matter samples from Rio de Janeiro City in December and SRM 1648 , excited at $337.1 \mathrm{~nm}$

gel and activated charcoal. Pyrene is relatively abundant in urban air particulate matter and owing to its chemical stability is frequently used as a model probe..$^{20}$ The fluorescence results can be seen on Figure 5. Pyrene on silica produces a strong characteristic fluorescence signal that totally disappears for the same pyrene concentration on charcoal. These results confirm that black carbon acts as if it were a quenching agent since it absorbs the excitation photons and does not fluoresce. In order to take this problem into account, we corrected fluorescence values using a factor that accounts for the increasing black carbon

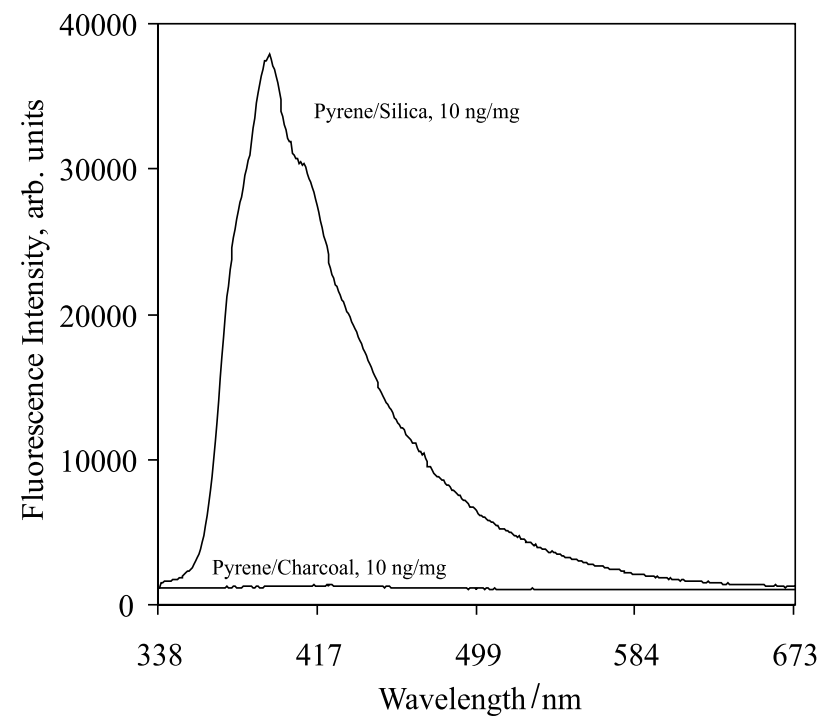

Figure 5. Laser-induced fluorescence spectra of 10 nanogram per milligram of pyrene deposited onto silica gel and also activated charcoal, excited at $337.1 \mathrm{~nm}$ 
fraction in each sample. Since black carbon is the deposition substrate, not the quartz filter, black carbon fraction in each sample can be estimated as $\mathrm{f}_{\text {black carbon }}=$ $\mathrm{F}(\mathrm{R})_{\text {sample }} / \mathrm{F}(\mathrm{R})_{\text {black carbon }}$, where $\mathrm{F}(\mathrm{R})_{\text {black carbon }}$ is constant and was determined for pure carbon black. Even though the corrected values shown in Figure $3 \mathrm{e}$ are closer to those of Figures $3 \mathrm{a}$ and $3 \mathrm{~b}$, the correction factor does not fully account for black carbon quenching effect.

Correlation factors of 0.93 and of 0.88 were obtained comparing the results provided by the diffuse reflectance method and by GC/MS for total PAH content expressed in $\mathrm{ng} \mathrm{m}^{-3}$ and in $\mathrm{ng} \mathrm{mg}^{-1}$ respectively.

The fact that the correlation of PAH's content versus Remission Function is indirect (through the carbon black content) does not mean that it does not exist. The comparison of Figures $3 \mathrm{a}, 3 \mathrm{~b}$ and $3 \mathrm{c}$ clearly supports this view. Other authors ${ }^{22}$ used diffuse reflectance measurements (but not the remission function) for PAHs evaluation on fly ash, although with a less accurate formulation, which we correct here.

For laser induced fluorescence it is well known that the intensity varies with the square root of the concentration of the fluorescent probe for low loaded samples, reaching a plateau (saturation) for high loadings as we have shown in previous publications. ${ }^{8,9}$ In spite of the low number of samples used in this work this behaviour was found. For the lower loaded samples situated in the non saturated region a linear relation of the intensity of fluorescence versus the square root of the concentration was found with a correlation factor of 0.77 .

The results presented in this work agree quite well with the general pattern observed for other probes adsorbed on solid surfaces. ${ }^{8,9}$

Later, 8 new samples collected in June and September (winter months) at the same places, were also analysed and the overall results lead to the same behaviour, showing, once more, the method's validity.

Fluorescence certainly has its origin in the PAHs present in the samples as showed by the absence of significative emission obtained from the blanks (filters, filters with black carbon, filters with air particulate matter after PAHs removal by solvent extraction).

The similarity of the emission curves obtained from our samples and from the standard material used also support this conclusion (see Figure 4).

Laser induced fluorescence methodology is strongly influenced by external factors (content of black carbon, thickness of the collected film, etc) ${ }^{6,12}$ In fact, laser fluence affects the penetration depths and in this way it may influence the obtained results. In all experiments laser fluence of the excitation radiation was constant.

In the diffuse reflectance experiments we have measured the diffuse transmission and concluded that it was zero or negligible for all samples, within experimental error. Reflectances were also measured with different excitation areas and also with 2 or 3 filter samples superimposed. Again, results were coincident within experimental error.

Lens were also used to diverge the laser excitation beam $(1.3 \mathrm{~mJ}$ per pulse at $337 \mathrm{~nm})$, as well as neutral density filters, reducing the number of photons per square centimetre of excitation, at least in a 20 times range. Within experimental errors, all the luminescence results agree with those presented in Figure 3e.

All these points are consistent with optically thick samples pointing to the validity of Kubelka-Munk treatment. It means that fluorescence signal is proportional to square root of concentration in a reasonable way, (in spite of the fact that several PAHs are adsorbed on the air particulate and not only one), as Figure 3e shows. So, for low PAH concentrations a linear calibration can be obtained, but not for high concentrations, as previously shown. ${ }^{8}$

\section{Conclusions}

Ground-state diffuse reflectance proved to be by itself a good technique for the evaluation of total PAH content of urban particulate matter, since results directly correlate with data obtained by conventional chromatographic techniques. Laser-induced luminescence appeared to be also a good technique for less concentrated samples. The methods showed to be efficient on total PAH evaluation at a local scale. Both techniques are valuable alternatives as screening techniques to air quality monitoring, with the advantage of being fast and therefore allowing a larger number of observations. Furthermore, the necessary equipments are relatively simple and can be easily adapted for in situ field evaluations since compact lasers and diffuse reflectance spectrophotometers are commercially available.

\section{Acknowledgements}

The authors thank ICCTICAPES for financial support and Dr Leila S.R. Brickus for help during sample collection in Rio de Janeiro. A.S.O. thanks FCT for a Post-Doctoral fellowship (BPD Praxis XXI 14182/97). M.B.F. thanks FIOCRUZ/FAPERJ for a Visiting Researcher fellowship. Equipment was financed by project Praxis/P/Qui/10023/98. 


\section{References}

1. Kortüm, G.; Reflectance Spectroscopy: Principles, Methods, Applications, Springer-Verlag: Heidelberg, Germany, 1969.

2. Kessler, R.W.; Wilkinson, F.; J. Chem. Soc. Faraday Trans. I, 1981, 77, 309.

3. Wilkinson F.; Willsher C.; J. Chem. Phys. Lett. 1984, 104, 272.

4. Wilkinson, F.; Kelly, G. P. In Handbook of Organic Photochemistry; Scaiano, J.C. ed.; CRC Press: Boca Raton, 1989, Vol.1, ch. 12 .

5. Wilkinson, F.; Kelly, G. P. In Photochemistry on Solid Surfaces; Anpo, M.; Matsuara, T., eds.; Elsevier: Amsterdam, 1989, ch. 2 .

6. Botelho do Rego, A. M.; Vieira Ferreira, L. F. In Handbook of Surfaces and Interfaces of Materials; Nalwa, H. S., ed.; Academic Press: New York, 2001, vol 2, ch. 7.

7. Vieira Ferreira, L. F.; Oliveira, A. S.; Wilkinson, F.; Worrall, D. R.; J. Chem. Soc. Faraday Trans. 1996, 92, 1217.

8. Vieira Ferreira, L. F.; Freixo, M. R.; Garcia, A. R.; Wilkinson, F.; J. Chem. Soc. Faraday Trans., 1992, 88, 15.

9. Vieira Ferreira, L. F.; Garcia, A. R.; Freixo, M. R.; Costa, S. M. B.; J. Chem. Soc. Faraday Trans. 1993, 89, 1937.

10. Vieira Ferreira, L. F.; Netto-Ferreira, J. C.; Khmelinskii, I. V.; Garcia, A. R.; Costa, S. M. B.; Langmuir 1995, 11, 231.

11. Vieira Ferreira, L. F.; Oliveira, A. S.; Netto-Ferreira, J. C. In Fluorescence Microscopy and Fluorescent Probes 3; Kotik, A., ed.; Espero Publish.: Prague, Czech Republic, 1999, p. 199.
12. Vieira Ferreira, L. F.; Química 2000, 72, 28.

13. Hurtubise, R J.; Anal. Chim. Acta 1997, 351, 1.

14. Cachier, H. In Atmospheric Particles; Harrison, R. M., Van Grieken, R., eds.; John Wiley \& Sons: Chichester, UK, 1998, p. 295.

15. Baek, S. O.; Field, R. A.; Goldstone, M. E.; Kirk, P. W.; Lester, J. N.; Perry, R.; Water, Air and Soil Pollution 1991, 60, 279.

16. Law, R. J.; Biscaya, J. L.; Marine Pollution Bulletin 1994, 29 , 235.

17. Wise, S. A.; Benner, B. A.; Chesler, S. N.; Hilpert, L. R.; Vogt, C. R.; May, W. E.; Anal. Chem. 1986, 58, 3067.

18. Fernandes, M. B.; Brickus, L. S. R.; Moreira, J. C.; Cardoso, J. N.; Rev. Environm. Health 1999, 14, 145.

19. Oliveira, A. S.; Almeida, P.; Vieira Ferreira, L. F.; Collect. Czech. Chem. Commun. 1999, 64, 459.

20. Fernandes, M. B.; Brickus, L. S. R.; Moreira, J. C., Cardoso, J.N., Neves, F.L. In Environmental Geochemistry in Tropical Countries; Abrão, J.J., Santelli, R.E., Duursma, E.K., eds.; Springer-Verlag:Heidelberg: Germany. In Press.

21. Alarie, J. P.; Vo-Dinh, T.; Talanta 1991, 38, 529.

22. Behymer, T. D.; Hites, R.A.; Environm. Sci. Technol. 1988, 22, 1311.
Received: June 11, 2001

Published on the web: March 6, 2002 